\title{
SENATUS ET ECCLESIA: A TRANSLADAÇÃO DA AUCTORITAS ENTRE UMA ARISTOCRACIA SENATORIAL E UMA ARISTOCRACIA EPISCOPAL
}

\author{
Janira Feliciano Pohlmann ${ }^{1}$ \\ Otávio Luiz Vieira Pinto ${ }^{2}$
}

RESUMO: A partir de uma seleção de autores da Antiguidade Clássica e Tardia e períodos relevantes à nossa pesquisa, nos propomos, neste trabalho, a compreender o caminho percorrido pela actoritas na transladação deste "poder" da esfera senatorial para a eclesiástica. Para tanto, observamos mudanças significativas nas esferas administrativas, políticas, sociais e religiosas que possibilitaram e impulsionaram esta transferência de competências e a substituição do Senatus pela Ecclesia como grupo legitimador e conselheiro do imperator romanorum.

PALAVRAS-CHAVE: Senado; Eclésia; Auctoritas.

ABSTRACT: From a selection of authors from the Classical Antiquity, Late Antiquity and relevant epochs for our research, we intend, in this work, to comprehend the performed path of the auctoritas in the translocation of this "power" from the senatorial sphere to the ecclesiastical sphere. To do so, we observe significant changes in the administrative, political, social and religious spheres that made this possible and launched the transfer of authorities and the substitution of the senatus for the ecclesia as a legitimating group and counselor of the imperator romanorum.

KEY-WORDS: Senate; Ecclesia; Auctoritas.

\section{Senatus et Res Publica: uma perspectiva ciceroniana}

As Leis regem os Magistrados, e os Magistrados regem o
Povo $^{3}$. Para Cícero, essa era a ordenação social esperada da

${ }^{1}$ Graduanda do curso de Licenciatura e Bacharelado em História da UFPR e Bolsista PIBIC-Balcão/CNPq/NEMED - UFPR. Orientação do Prof. Dr. Renan Frighetto.

${ }^{2}$ Graduando do curso de Licenciatura e Bacharelado em História da UFPR e Bolsista PIBIC-CNPq/NEMED - UFPR. Orientação do Prof. Dr. Renan Frighetto. 
República. Por sua vez, a própria República possuía essa conotação de interdependência entre povo (populus), leis (lex) e magistrados (magistratus); Cícero entendia a Res Publica como um governo norteado pelos interesses comuns e o direito advindo de um consenso ${ }^{4}$. Conforme este político, a virtude, tão prezada no Mundo Clássico, se consolidava na prática e seu melhor uso consiste em governar a República e converter em obras as palavras que se ouvem nas escolas 5 . O consenso desta administração, assim como a gênese das leis e o corpo de magistrados eram representados por um órgão que guiava justamente este espírito republicano: o Senado (senatus). A primazia senatorial como um dos elementos caracterizadores da sociedade romana era representada até mesmo nos estandartes legionários pela famosa sigla SPQR - senatus populesque romanum (Senado e povo romano).

O Senado, antes de um componente do binômio senatus / populus, era um canal aristocrático, instituição de manutenção de um corpo de optimates - os homens preparados, educados para governar, portadores da humanitas e do mos maiorum, tradicionais membros de gentes ancestrais ${ }^{6}$, responsáveis não apenas pelo bom funcionamento da política romana, como também pela negação de uma administração pessoal e monárquica, ou seja, centralizada. A prática,

\footnotetext{
${ }^{3}$ Ut enim magistratibus leges, ita populo praesunt magistratus, vereque dici potest, magistratum esse legem loquentem, legem autem mutum magistratum. In: Cic. De Legibus, III, 2.

${ }^{4}$ Est igitur, inquit Africanus, res publica res populi, populus autem non omnis hominum coetus quoquo modo congregatus, sed coetus multitudinis iuris consensu et utilitatis communione sociatus. Cic. De Re Publica, I, 39 apud PEREIRA, Maria Helena da Rocha. Idéias morais e políticas dos romanos. In: Estudos de História da Cultura Clássica. II volume - Cultura Romana. Lisboa: Fundação Calouste Gulbekian, 2002, p. 373-379.

${ }^{5}$ CÍCERO, Marco Tulio. Da República, Livro I, II, p. 17.

${ }^{6}$ Humanitas, para os romanos, aproximava-se da idéia grega de Paidéia ( $\left.\pi \alpha \iota \delta \varepsilon i ́ \alpha\right)$, que, por sua vez, era o conceito que designava a educação plena e a formação verdadeira dos homens. Mos maiorum, a "tradição dos maiores", faz parte da idéia de que certas famílias - as gentes - remontavam a um ancestral mítico (como Hércules) e, por sua antiguidade, possuíam primazia sobre as outras.
} 
porém, se mostrava diferente destes princípios; sabemos que no tempo de Cícero, o poder pessoal tornava-se cada vez mais presente, e o regimento da República concentrava-se paulatinamente na mão de um ou dois personagens políticos - para Cícero, o poder pessoal significava monarquia, um governo bárbaro e incompatível com os preceitos e a tradição romana.

Sob o ponto de vista ciceroniano, a ordem somente seria mantida se o poder permanecesse nas mãos daqueles preparados para governar corretamente: os senadores, uma vez que estes magistrados tinham força, liderança e conhecimento para prescrever as atitudes corretas e úteis através das leis ${ }^{7}$. Estes homens davam voz às regras e regiam o povo de acordo com as normas. Segundo Cícero, o magistrado é a lei que fala. Sendo assim, os cidadãos deviam obedecer a estes homens que, por sua vez, obedeciam às leis. O poder de legislar cabia somente aos senadores, os únicos capazes de desempenhar esta respeitável função. Portanto, o Senado era a lei. Percebemos, então, que até este momento, ao menos sob a visão senatorial, o Senado é tido como a mais importante instituição política do imperium romanorum. As leis eram utilizadas para conduzir os povos livres, enquanto o poder régio comandava os bárbaros. Por isso os magistrados se faziam tão necessários, visto que, sem eles não haveria República; sem a República, a liberdade não seria mantida, nem a humanitas, nem a ordem, nem a justiça... Roma não existiria. Somente através do Senado Roma seria Eterna. Desta forma, Cícero pretendia assegurar ao Senatus o usufruto de dois importantes "poderes" romanos: o imperium e a auctoritas ${ }^{8}$, pois, somente desta forma, a liberdade dos romanos seria mantida.

\footnotetext{
${ }^{7}$ CÍCERO, Marco Tulio. De las leyes, Libro III.

${ }^{8}$ Entendemos por auctoritas um poder que é reconhecido a um indivíduo ou grupo, enquanto o imperium é o poder de mando, o poder de administrar questões temporais. Conforme Pereira, a auctoritas confere maior peso a um poder já existente, é um acréscimo, por isso, cabia aos magistrados a potestas, ao Senatus, a auctoritas e os romanos, a libertas. In: PEREIRA, Maria Helena da Rocha. Idéias morais e politicas dos romanos. In: Estudos de História da Cultura Clássica. II volume - Cultura Romana. Lisboa: Fundação Calouste Gulbekian, 1984.
} 
Demonstramos, pois, que a proteção ciceroniana ao papel desempenhado pelo Senado carrega consigo uma ideologia que perseguia a legitimação desta instituição em tempos de conflitos e transformações sociais e políticas. Esta sociedade clássica nos exibe seu imperium cada vez mais centralizado em um indivíduo e seqüestrado das mãos senatoriais.

\section{Senatus et Imperium: a perspectiva de Símaco}

Os séculos IV e V já nos apresentam um outro cenário: o imperium está consolidado na figura do imperator, mas a ordem senatorial se mantém. Como isto seria possível, visto que a razão primeira do Senado era o usufruto do poder de mando (imperium potestate)?

Lembremos que, assim como os conceitos se modificam com o passar dos tempos, as instituições também são adaptadas às transformações sociais, políticas e religiosas de distintos contextos. Enquanto são úteis para a sociedade, elas se mantêm, mas como requisito para isto, devem ser moldadas conforme a nova realidade.

No contexto de Quinto Aurélio Símaco ${ }^{9}$, não se questionava mais a centralização do imperium nas mãos do imperator. A transladação deste poder do Senado para o imperator era fato consumado e, mesmo assim, os romanos mantinham sua ordenação política, administrativa e social.

Neste cenário da Antiguidade Tardia, o exercício de um cargo público estava condicionado ao mérito. Conforme o Discurso $1^{10}$ de Símaco, as virtudes conduziam à Cúria. Em contrapartida, em seu segundo Discurso ${ }^{11}$, Símaco exalta os recentes feitos de Valentiniano

9 Quintus Aurelius Symmachus Eusebius desempenhou vários cargos na administração pública, sendo o mais importante deles o de Prefeito da Urbe (384385), magistratura inferior apenas ao Prefeito do Pretório.

${ }^{10} \mathrm{O}$ Discurso 1 de Símaco é escrito em honra a Valentiniano I para comemorar o primeiro ano de consulado deste personagem.

${ }^{11}$ O Discurso 2 de Símaco também é escrito para Valentiniano I, por ocasião de sua designação ao seu terceiro consulado. 
I e declara que o consulado é uma recompensa demasiadamente modesta perante o esforço deste governante. Outra modificação é observada, visto que, na época clássica, juntamente com os pretores, os cônsules eram os homens públicos mais importantes da República. Enquanto para os contemporâneos de Símaco, o Consulado já não possuía grande proeminência e, apesar dos senadores ainda comporem um grupo destacado, conforme afirma Símaco, possuir riquezas não era fundamental para $\mathrm{o}$ ingresso na Cúria. $\mathrm{O}$ que iluminava o caminho para a vida política eram as virtudes e o mérito, muito mais do que o patrimônio ${ }^{12}$.

Símaco era um verdadeiro amante da tradição; defendia a conservação da literatura Antiga e evocava as honras à filosofia e aos símbolos pagãos. Sua preocupação com a manutenção dos costumes dos maiores cidadãos (mos maiorum) buscava preservar a eternidade romana e, conseqüentemente, defender os privilégios da ordem senatorial, na qual estava integrado, juntamente com outros pagãos e, também com representantes do cristianismo.

Aos olhos deste político, o Senado era uma ordem ilustríssima, perfeita em suas ações, guardiã do mos maiorum e estandarte da sempre roma ceterna. Contudo, em seu Informe 3, endereçado a Teodósio (porém provavelmente enviado também a Valentiniano e Arcadio - devido a expressão "senhores imperadores" -), Símaco identifica o "ilustríssimo Senado" como pertencente ao imperator. Esta atitude, totalmente reprovada em épocas ciceronianas, é perfeitamente aceitável - e normal - na realidade tardo-antiga. Neste ínterim, uma das missões senatoriais era perseguir aqueles que preferiam seu próprio poder ao do princeps $^{13}$.

2 SÍMACO, Discurso 1, 23, p. 185: "Puedo decir que una vez ahuyentadas las intrigas se han devuelto los cargos públicos a la virtud y que ya no son las riquezas sino las conductas que tienen la vía abierta a las insignias de las magistraturas, que ahora son equivalentes a la suerte del campamento y la de la curia."

13 Símaco intercala as expressões imperator e princeps quando se refere aos imperatores (Valentiniano II, Teodósio e Arcadio). 
Assim, o Senado deveria auxiliar no combate aos conflitos, as guerras e, essencialmente, a usurpação.

Ao ser nomeado para o cargo de Prefeito da Urbe, Símaco escreve dois informes ${ }^{14}$ aos imperatores para manifestar sua gratidão pela designação a tal magistratura e solicitar apoio imperial para exercer suas tarefas. Primeiramente, observamos que a nomeação para o ilustre cargo de Prefeito de Roma não era tarefa da ordem senatorial, mas sim do imperator que também podia depor este magistrado. As eleições e destituições não se faziam mais, apenas, no âmbito interno da ordem senatorial. Cabia ao governante do imperium indicar os nomes que ocupariam os mais destacados cargos públicos. Em segundo lugar, verificamos o pedido de auxílio imperial para correta administração pública, pois, sem este amparo, as atividades governamentais não transcorreriam retamente. Percebemos esta necessidade em vários Informes nos quais Símaco freqüentemente solicita ou agradece aos imperatores o envio de alimentos (geralmente grãos e azeite) ou dons destinados à celebração de jogos.

Tanto em seu Informe 1, quanto no Informe 2, o Prefeito da Urbe recorda aos imperatores que os bons magistrados se fazem para favorecer o princeps, o qual deve velar pela causa comum juntamente com os senadores. Símaco, ainda declara que, com o apoio destes bem preparados homens públicos, o imperator transforma a fama de sua época em grande glória ${ }^{15}$. Assim, o Prefeito da Urbe revela ilustres tarefas senatoriais: resguardar o bem comum, propagar o correto governo e manter a tradição das virtudes.

Desta forma, notamos que o Senado mantém seu prestígio perante a sociedade romana. Já não é a lei, como defendia Cícero,

\footnotetext{
${ }^{14}$ SÍMACO, Informe 1, pp. 33-34; Informe 2, pp. 34 - 35.

${ }^{15}$ SÍMACO, Informe 1, 3, p. 34: "Sin duda es el favor de los príncipes lo que hace buenos magistrados y siempre fluyen desde vuestro carácter las virtudes de os dirigentes". Informe 2, 3, p. 35: "A vuestro numen le corresponderá velar por la causa común, pues con buenos magistrados la fama de la época adquire una gloria mayor que la lograda por los gobernantes".
} 
todavia, tem como missão o aconselhamento do imperator para que este indivíduo governe conforme virtuosos princípios, assim a ceternitate romanae seria garantida.

Caso o princeps mantivesse em seu círculo de conselheiros homens bem preparados, estudiosos e virtuosos, defensores da causa comum e, conseqüentemente, do reto governo, este governante obteria sucesso. Caso contrário, como afirma Frighetto ao lembrar as recomendações dadas por Aelius Lampridius a Constantino ${ }^{16}$, o fracasso era certo. Frighetto aponta que, em sua Vita Alexander Seuerus - integrada a Historia Augusta -, Lampridius toma como exemplo a péssima atitude de Alexandre Severo que se serviu de maus amigos (amici mali) como conselheiros e não ouviu as advertências senatoriais. Vítima da inveja de seus falsos amigos, o último imperator da dinastia dos Severos foi morto. Sendo assim, Símaco invoca para o senatus o mérito de orientar corretamente o grande governante na ação de bem administrar o imperium, uma vez que os magistrados são os optimates e, naturalmente, defensores da liberdade, da humanitas, da ordem, da justiça... de Roma. Por conseguinte, enquanto o poder de mando (imperium potestate) pertencia ao imperator, cabia ao senatus a auctoritas.

Cícero concebia um Senado possuidor e usuário do imperium potestate. Os magistrados, pessoas extremamente cultas, defensoras e guardiãs das tradições, eram os responsáveis pelo reto governo romano. Símaco, por sua vez, apesar de leitor e seguidor de princípios ciceronianos, exaltava a importância do aconselhamento senatorial àquele que usufruía o poder de mando, o imperator. Outra questão que diferencia estes dois políticos é o convívio de Símaco com senadores que compartilhavam crenças religiosas distintas da sua. Após os Concílios do século IV, em especial o Edito de Milão de 313 , o cristianismo se tornou mais uma das religiões do imperium

\footnotetext{
16 FRIGHETTO, Renan. Idéias e práticas políticas na Antiguidade Tardia: construções ideológicas, exercício do poder político e a força da tradição política do mundo clássico greco-latino. Texto apresentado no Evento Transferências Culturais (realizado na UFPR $-1^{\circ}$ Semestre de 2008). A ser publicado.
} 
e os cristãos, cada vez mais, se faziam presentes nos cargos públicos da sociedade romana. Entretanto, as divergências entre a filosofia pagã e a teologia cristã não ocasionavam grandes conflitos políticos entre os senadores, os quais continuavam a defender, quer fossem pagãos ou cristãos, a correta administração do imperium por parte do princeps, sempre com o auxílio senatorial ${ }^{17}$. Deste modo, a Cúria se apresenta, sem grandes agitações, como palco de um cenário misto, composto por adoradores dos antigos deuses e por seguidores de Cristo.

\section{Senatus et Christianitas: a perspectiva de Próspero}

Esta amálgama senatorial, paulatinamente, recebeu mais membros que professavam o cristianismo. Conforme Bravo, houve uma progressiva implantação da teologia dos cristãos nos mais distintos estratos sociais "particularmente, en el ejército y la administración"18. Blásquez destaca que a estratégia política de Constantino e de seus sucessores tinha como um de seus pilares a unidade proclamada pela eclésia ${ }^{19}$. Nesta sociedade romana em transformação, o cristianismo serviu como suporte ideológico do imperium potestate, pertencente a um único cidadão: o imperator.

Da mesma maneira, em meio a uma sociedade que recebia em seu seio os mais diversos grupos e, cada vez mais, notava germanos e outras etnias em suas esferas administrativas, o elemento de coesão e unidade não poderia ser apenas uma instituição que

\footnotetext{
${ }^{17}$ No caso da reivindicação de Símaco para a restauração do altar da deusa Vitória e das prerrogativas do culto pagão, em seu Informe 3, o Prefeito de Roma demonstra todo seu amor a Antiga Tradição e, mesmo assim, tem sua oratória e erudição elogiadas por importantes cristãos como Ambrósio de Milão e Aurélio Prudêncio Clemente.

18 BRAVO, Gonzalo. Historia del mundo antiguo: Una introducción crítica. Madri: Alianza Editorial, S.A., 2005, p. 536.

19 BLÁZQUEZ, José María. "La política imperial sobre los cristianos. De la Tetrarquía a Teodosio". In: Cristianismo primitivo y religiones mistéricas. Cátedra, 1995, pp. 274-276.
} 
congregasse, justamente, a tradição e a legitimação inerente aos antigos romanos. Assim, ainda que o Senatus se mantivesse como um elemento caracterizador do imperium romanorum, ele via sua influência e seu poder pragmático fluindo justamente para o universalismo cristão. Enquanto universal, o imperium passava a espelhar, na Antiguidade Tardia, a religião como elemento de coesão política e social.

Neste cenário que une, então, uma religião dominante e uma nova face social (marcada em especial pelos ingressados germanos), procura-se fundamentar o poder num elemento mais abrangente: ao Senatus, instrumento de tradição e legitimação histórica, caberia o aconselhamento e a auctoritas num ambiente mais próximo ao imperator. Mas seria a ecclesia, agora, a assumir o papel de reger os aspectos sociais e morais do mundo romano.

Um claro exemplo desta crescente primazia episcopal como elemento de coesão político-social é o de Próspero de Aquitânia. Discípulo de Agostinho de Hipona e funcionário eclesiástico sob o báculo do papa Leão I, Próspero nos legou uma série de trabalhos menores e relacionados a questões doutrinais (trabalhos como De uocatione omnium gentium e De gratia Dei et libero arbitrio são algumas de suas obras que lidam com querelas religiosas), mas o eco mais duradouro de sua perspectiva é o epitoma chronicon. Feita aos moldes da Crônica de Eusébio de Cesárea, Próspero procurava provavelmente, com esta obra, atestar a oficialidade de seu cargo e de suas influências - na medida em que a Crônica eusebiana tornarase uma "história oficial" de um rejuvenescido imperium cristianizado pela mão de Constantino, o método cronistico era uma das formas de se registrar a história a partir de uma posição oficial. Um dos principais personagens de seu chronicon, porém, é o papa; como membro de um corpo eclesiástico, Próspero vê na figura do Bispo de Roma a verdadeira universalidade política e cultural do Império. Não à toa, nos momentos em que concede atenção ao problema "bárbaro", Próspero enfatiza a negociação feita por Leão I com 
chefes e reis tribais, tal qual Átila e Genserico, e não a dos imperatores (Teodósio II e ver o outro):

Aceitou este negócio com o consul Aviêno e com o prefeito Trigetio o beatíssimo Papa Leo apoiado no auxílio de Deus, ciente dos trabalhos pios que nunca abandonou. E não seguiu outra coisa além das que a fé prejulgara. Por isso, tendo toda a legação aceitado favoravelmente, o rei alegrou-se com a presença do Sumo Sacerdote, e [o rei] avisou abster-se da guerra retirou-se, para além do Danúbio, com a promessa de paz. ${ }^{20}$

Num segundo momento, Próspero atesta a importância papal nas negociações com Genserico:

Após esta saída de Máximo, imediatamente, a digna escravidão romana seguiu com muitas lágrimas, e Genserico manteve presa toda a cidade vazia, e correu para encontrar, além das portas, o bispo São Leão, cuja súplica ele guiou para Deus, já que todas as coisas eram de seu próprio poder, depois que a cidade foi entregue para si, seria, contudo, desviado do fogo, da matança e dos suplícios ${ }^{21}$.

20 "Suscepit hoc negotium cum viro consulari Avieno, et viro praefectorio Trigetio beatissimus papa Leo

auxilio Dei fretus, quem sciret numquam piorum laboribus defuisse. Nec aliud secutum est quam praesumpserat fides. Nam tota legatione dignanter accepta, ita summi sacerdotis praesentia rex gavisus est, ut et bello abstineri praeciperet, et ultra Danubium promissa pace discederet "(Prosp. Aqui. Epitoma chronicon)". A versão aqui utilizada encontra-se em http://www.documentacatholicaomnia.eu/02m/0390-

0463,_Prosperus_Aquitanus,_Chronicum_Integrum_In_Dua_Partes_Distributum, MLT.pdf. O epitoma chronicon editado por Mommsen, com pequenas diferenças ortográficas, pode ser acessado em http://mdz10.bibbvb.de/ db/bsb00000798/images/index.html?id=00000798\&fip $=201.21 .175 .71 \& \mathrm{n}$ $\mathrm{o}=9 \&$ seite $=482,1367$.

21 "Post hunc Maximi exitum, confestim secuta est multis digna lacrymis Romana captivitas, et Urbem omni praesidio vacuam Gensericus obtinuit, occurrente sibi extra portas sancto Leone episcopo, cujus supplicatio ita eum Deo agente fenivit, ut cum omnia potestatis ipsius essent, tradita sibi civitate, ab igne

tamen et caede atque suppliciis abstineretur." (Prosp. Aqui. Epitoma chronicon. 754). A versão aqui utilizada encontra-se em http://www.documentacatholicaomnia.eu/02m/03900463,_Prosperus_Aquitanus,_Chronicum_Integrum_In_Dua_Partes_Distributum, MLT.pdf. O epitoma chronicon, editado por Mommsen, com pequenas diferenças 
Ambas as passagens são paradigmáticas: Próspero indica a primazia do líder religioso na lida dos assuntos políticos. É pela palavra de Leão que se desenrola o jogo romano e é a presença papal o símbolo de poder nas comitivas. Ainda que sob os auspícios do imperator e acompanhado de membros da administração, o Papa é claramente, na perspectiva de Próspero, a "lei romana", a moral e, de certa maneira, a representação imperial.

\section{Senatus et Ecclesia: um paradigma aristocrático}

Percebemos que o Senatus, símbolo da República de Cícero, não se esvaziou com o passar das décadas do imperium romanorum. Contudo, foi adaptado às novas realidades daquela sociedade. Lembremos que as idéias e instituições não são criadas aleatoriamente, mesmo quando relacionadas à política e ao poder. Elas respondem as necessidades de seu contexto. Por isso, devem ser moldadas conforme seu tempo.

O senatus torna-se mais e mais, na medida em que é reduto de tradição e história, um elemento de auctoritas diante do círculo imperial; fundamentalmente, um elemento de aconselhamento. Mas é justamente por seu caráter meritório e seletivo que a Cúria distanciase da proposta de universalidade imperial, recorrente desde pelo menos Constantino, quando o mundo político romano passa a contar, oficialmente, com o ideal cristão em seu norte administrativo e ideológico. O corpo episcopal, então, alçado primeiro à legalidade e, em seguida, à primazia político religiosa (com Constantino e Teodósio I), passa a renovar o elemento de influência sobre o populus.

Outrora Cícero dissera que as leis regem os magistrados, e os magistrados regem o povo. O senatus, portanto, era a instituição que transpunha esta ideologia para a regência prática. Com o advento do

\footnotetext{
ortográficas, pode ser acessado em http://mdz10.bibbvb.de/ db/bsb00000798/images/index.html?id $=00000798 \&$ fip $=201.21 .175 .71 \& \mathrm{n}$ $\mathrm{o}=9$ \&seite $=496,1375,20-30$.
} 
princeps, do imperator e, posteriormete, do imperator christianum (?), o senatus enclausura-se entre as esferas aristocráticas e, a transcendência institucional que atinja também o populus passa a centrar-se na religião. Há, como vimos, a existência de um corpo senatorial e, inclusive, como Símaco, personagens que conservam elementos tradicionais (como o paganismo), porém, no momento de fragmentação, senatus populesque olham para a universalidade religiosa. Assim, poderíamos dizer, neste momento, que Deus rege os bispos, e os bispos regem o povo.

Observamos, pois, que o senatus se tornou uma instituição de aconselhamento político-adminsitrativo do imperator, tendo sua esfera de atuação restrita ao círculo deste governante. Neste contexto, a ecclesia ocupou o vácuo de ação deixado pelos senadores junto ao populum; a par e passo, também se relacionava com o imperator e legitimava a política cada vez mais universal e centralizadora deste personagem. Desta forma, percebemos que, finalmente, a auctoritas deixa as mãos senatoriais para pertencer à ecclesia. Porém, visto que tanto o senatus quanto a instituição cristã são formados por membros da aristocracia romana, a auctoritas não abandonou o grupo de destaque da sociedade tardo-antiga. Portanto, a transladação deste poder ocorreu na esfera polítca-administrativa, mas não, social.

Os valores cristãos passaram a ser propagados no lugar das honras prestadas aos antigos deuses. Contudo, o grupo social responsável por reproduzir estas novas considerações que guiavam a sociedade tardo-antiga permaneceu o mesmo: a aristocracia. $\mathrm{Na}$ época clássica, era proveniente das gentibus ${ }^{22}$; durante a Antigüidade Tardia, procedia daqueles que proclamavam os "ensinamentos" de Cristo.

\section{BIBLIOGRAFIA}

${ }^{22}$ Gens, gentis: famílias antigas consideradas portadoras da tradição e descendentes de ancestrais míticos. (gentibus: ablativo plural feminino $-3^{\mathrm{a}}$ decl.) 
CÍCERO, Marco Tulio. Da República (Livro I). Tradução para o português: Amador Cisneiros. Coleção: Mestres Pensadores. São Paulo: Editora Escala.

. De las leyes (Libro III). Versão para espanhol: N. A. Rufino. Buenos Aires: Editorial TOR.

HIDÁCIO DE CHAVES. Cronicon de Idacio: obispo de Chaves. Trad. Julio Campos. Salamanca: Ediciones Calasancias, 1984.

- Crónica de Idácio: descrição da invasão e conquista da Península Ibérica pelos Suevos (séc. V). Versão e anotações de José Cardoso. Braga: Universidade do Minho, 1982.

LEÃO MAGNO. Sermões. São Paulo: Paulus, 1996.

PRÓSPERO DE AQUITÂNIA. Prosperi Tironis epitoma chronicon. In: http://mdz10.bib-bvb.de/ db/bsb00000798/images/index.html? seite $=354$.

PRUDÊNCIO. Contra Symmachus. In: BREPOLS, CLCLT, CDROOM, 1994.

SÍMACO EUSÉBIO, Quinto Aurélio. Cartas (Libros I - V). Introducciones, traducción y notas: José Antonio Valdés Gallego. Madrid: Editorial Gredos S.A., 2000.

. Informes - Discursos. Introducciones, traducción y notas: José Antonio Valdés Gallego. Madrid: Editorial Gredos S.A., 2003.

. praefecti urbis relationes. http://www.dmgh.de. Acesso em 03/05/2008.

BLÁZQUEZ, José María. La política imperial sobre los cristianos. De la Tetrarquía a Teodosio. In: Cristianismo primitivo y religiones mistéricas. Cátedra, 1995, pp. 265-289.

BRAVO, Gonzalo. Historia del mundo antiguo: Una introducción crítica. Madri: Alianza Editorial, S.A., 2005.

DREW, Katherine Fischer Drew (org.). The Barbarian Invasions Catalysts of a New Order. Huntington, New York: Robert E. Krieger Publishing Company, 1977.

ELBERTI, Arturo. Prospero d'Aquitania: Teologo e discepolo. Roma: Edizioni Dehoniane, 1999.

FREND, W.H.C. A new eyewitness of the barbarian impact on Spain, 409-419. In: Antigüedad y Cristianismo VII - Cristianismo y 
Aculturacion en tiempos del Imperio Romano. Murcia, Universidad de Murcia, 1990.

FRIGHETTO, Renan. Idéias e práticas políticas na Antiguidade Tardia: construções ideológicas, exercício do poder político e a força da tradição política do mundo clássico greco-latino. Texto apresentado no Evento Transferências Culturais (realizado na UFPR $-1^{\circ}$ Semestre de 2008). A ser publicado.

- Algumas considerações: o poder político na Antiguidade Clássica e na Antiguidade Tardia. Revista Stylos - Instituto de Estudios Grecolatinos Francisco de Novoa, vol. 13, Buenos Aires, 2004, pp. 37-47.

HEATHER, Peter. The Fall of the Roman Empire: a New History of Rome and the Barbarians. Oxford, New York: Oxford University Press, 2007.

HIDALGO DE LA VEGA, María José. Algunas reflexiones sobre los limites del olkoumene en el Imperio Romano. In: Gerión, vol. 23, $\mathrm{n}^{\mathrm{o}} .1$, Madri, 2005, pp. 271-285.

MATHISEN, Ralph W. Barbarian Bishops and the Churches "in Barbaricis Gentibus" During Late Antiquity. In: Speculum, Vol. 72, No. 3. (Jul., 1997), pp. 664-697.

PEREIRA, Maria Helena da Rocha. Idéias morais e políticas dos romanos. In: Estudos de História da Cultura Clássica. II volume Cultura Romana. Lisboa: Fundação Calouste Gulbekian, 1984.

SALOR, Eustaquio Sánchez. Polémica entre cristianos y paganos. Madrid: Ediciones Akal, 1986.

SANCHÉZ LEÓN, Juan Carlos. Los Bagaudas: Rebeldes, Demonios, Mártires. Jaén: Universidad de Jaén, 1996.

SILVA, Gilvan Ventura da \& MENDES, Norma Musco (org.). Repensando o Império Romano: Perspectiva Socioeconômica, Política e Cultural. Rio de Janeiro, Mauad; Vitória, EDUFES, 2006. TEJA, Ramon. Auctoritas VS. Potestas: el liderazgo social de los obispos en la sociedad Tardo-Antigua. In: Emperadores, obispos, monjes y mujeres: Protagonistas del cristianismo antiguo. Madrid: Editorial Trotta, 1999. 